\title{
Producción y purificación de hidrógeno a partir de etanol mediante el proceso "Steam-Iron" en un reactor de lecho fijo
}

\author{
E. Hormilleja, P. Durán, J. Plou, J. Herguido, J.A. Peña \\ CREG (Grupo de Catálisis, Separaciones Moleculares e Ingeniería de Reactores) \\ Instituto de Investigación en Ingeniería de Aragón (I3A) \\ Universidad de Zaragoza, Mariano Esquillor s/n, 50018, Zaragoza, Spain \\ Tel. +34-976762390, Fax +34-976762043, e-mail: pauduran@unizar.es
}

\begin{abstract}
El presente trabajo plantea la viabilidad de utilizar fracciones alcoholicas de un bio-oil, o alcohol de origen biológico (bioetanol) como materia prima para la obtención de hidrógeno de alta pureza mediante un proceso redox cíclico ("Steam Iron Process") utilizando óxidos metálicos de alto contenido en hierro en un reactor de lecho fijo en operación discontinua.
\end{abstract}

\section{Introducción}

La sustitución de los combustibles fósiles por hidrógeno se presenta como una posible solución no sólo a la creciente escasez de éstos, sino también a la mayor presencia de gases de efecto invernadero y contaminación en la atmósfera. El hidrógeno supone una alternativa energética limpia, versátil y eficiente, que además puede ser obtenida a partir de recursos renovables [1]. Los bio-oils son combustibles renovables oxigenados que presentan un bajo índice de cetano, producidos mediante la pirólisis rápida de la biomasa y de alto carácter reductor. Su fracción alcohólica puede llegar a presentar porcentajes cercanos al $10 \%$ en peso, siendo el etanol el segundo compuesto mayoritario [2]. Asimismo, el bio-etanol, procedente de la fermentación de los azúcares contenidos en diversos materiales biomásicos como el azúcar de caña, la patata o diversos cereales por poner un ejemplo, constituye un buen punto de partida para la obtención de hidrógeno de alta pureza a partir de fuentes de energía renovable.

\section{Metodología experimental}

En el proceso "steam-iron", una corriente reductora (etanol) reacciona con óxido de hierro (III) obteniéndose hierro metálico. Posteriormente, se alimenta vapor de agua para reoxidar el hierro metálico a magnetita y producir a su vez hidrógeno de alta pureza. El presente trabajo muestra el estudio del proceso en un reactor de lecho fijo a lo largo de tres ciclos redox. El sistema experimental consta de un reactor de lecho fijo cilíndrico de cuarzo $\left(d_{i}=13\right.$ $\mathrm{mm}$ ), con un lecho de sólido de 2,12 g, donde el 75 \%w es óxido "triple" $\left(98 \% \mathrm{w} \mathrm{Fe} \mathrm{O}_{3}, 1,75 \% \mathrm{w} \mathrm{Al}_{2} \mathrm{O}_{3}\right.$ y $\left.0,25 \% \mathrm{w} \mathrm{CeO}_{2} \mathrm{dp}=160-200 \mu \mathrm{m}\right)$, y el $25 \%$ restante es sílice utilizada para reducir los perfiles de temperatura y evitar caminos preferenciales. La síntesis del óxido triple se realizó de acuerdo a un método sol-gel. Los aditivos se añaden con el fin de disminuir los efectos de sinterización (alúmina) y de mejorar la velocidad en las reacciones redox (ceria) [3].

Todos los experimentos fueron llevados a cabo a presión ambiente, y con un caudal total de gas de $250 \mathrm{NmL} / \mathrm{min}$ (suficiente para evitar el control difusional externo). En las etapas de reducción se usó etanol (presión parcial de 0,10 bar), mientras que las etapas de oxidación se realizaron añadiendo agua (presión parcial de 0,25 bar) en ambos casos el gas de dilución fue He. Se empleó Ar (presión parcial de 0,05 bar) como patrón interno. Tanto el etanol como el agua son dosificados como líquidos por medio de una bomba HPLC Shimadzu LC$20 A T$. Posteriormente, estos líquidos se vaporizan y alimentan al reactor. La adición de gases de dilución se realiza mediante medidores controladores de flujo másico. El aporte de calor al reactor se realiza mediante un horno eléctrico. Las temperaturas de reducción estudiadas fueron 650,700 y $750{ }^{\circ} \mathrm{C}$ (fijando $700{ }^{\circ} \mathrm{C}$ como temperatura estándar), mientras que la etapa de oxidación se realizó siempre a $500{ }^{\circ} \mathrm{C}$. Los gases de salida (agua y etanol inclusive) son analizados por medio de un cromatógrafo de gases (TCD) Agilent 7890A.

\section{Resultados}

La Figura 1 muestra la distribución de los gases de salida con el tiempo durante la etapa de reducción del primer ciclo, a $700{ }^{\circ} \mathrm{C}$. Al no detectarse la presencia de etanol en los gases de salida, se puede afirmar que existe una descomposición catalítica completa del etanol en contacto con el lecho. Durante los primeros instantes de la reacción (primeros $6 \mathrm{~min}$ ), tiene lugar la reducción de hematita $\left(\mathrm{Fe}_{2} \mathrm{O}_{3}\right)$ a magnetita $\left(\mathrm{Fe}_{3} \mathrm{O}_{4}\right)$ por efecto del 
$\mathrm{H}_{2}$ y $\mathrm{CO}$ obtenido al descomponerse el etanol. Durante una segunda etapa, el sólido continúa su reducción de magnetita a hierro metálico, paso que se completa a los 24 min. La velocidad de reducción en este caso es menor debido a la limitación termodinámica impuesta por el equilibrio entre las especies reductoras $\left(\mathrm{H}_{2}\right.$ y CO) y las oxidantes $\left(\mathrm{H}_{2} \mathrm{O}\right.$ y $\mathrm{CO}_{2}$ ). A partir de este momento, se observa un comportamiento estable debido tan sólo a la descomposición catalítica del etanol. La deposición de coque que tiene lugar durante la reacción queda reflejada en la gráfica por medio del aumento en la sobrepresión a lo largo del tiempo.

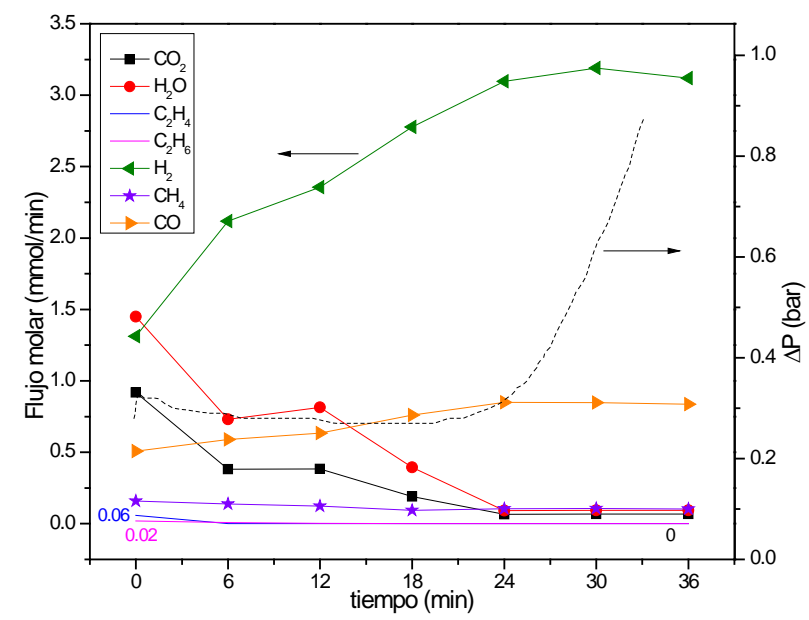

Figura 1. Reducción de óxido de hierro fresco a $700{ }^{\circ} \mathrm{C}$, con etanol (0,10 bar). Distribución de productos con el tiempo.

La Figura 2 presenta el efecto de la temperatura sobre la distribución de $\mathrm{H}_{2}$ y $\mathrm{H}_{2} \mathrm{O}$ para la etapa de reducción correspondiente al sólido fresco a lo largo del tiempo. Se observa que al incrementarse la temperatura aumenta la velocidad de reducción, y la restricción impuesta por el equilibrio $\mathrm{H}_{2} \mathrm{O} / \mathrm{H}_{2}$ y $\mathrm{CO}_{2} / \mathrm{CO}$ en el paso de $\mathrm{Fe}_{3} \mathrm{O}_{4}$ a $\mathrm{Fe}$ es menos apreciable, al presentar una duración menor en el tiempo (se acorta el tramo intermedio en el cual el flujo molar se mantiene estable a lo largo del tiempo). La disminución de la temperatura genera un aumento en la deposición de coque sobre la superficie del sólido (no mostrado).

En las etapas de oxidación correspondientes al primer ciclo, se obtienen generaciones de hidrógeno muy cercanas al máximo teórico posible (hasta magnetita); sin embargo, tras las reducciones segunda y tercera, se detecta un desgaste claro en el grado de recuperación de hidrógeno, debido principalmente a la sinterización. Con respecto a la generación de $\mathrm{CO}$ y/o $\mathrm{CO}_{2}$, debida a la posible gasificación del coque depositado, solamente fueron detectadas en los primeros minutos de las oxidaciones tras la reducción del óxido fresco a 700 y $750{ }^{\circ} \mathrm{C}$ (efecto no mostrado) con flujos molares detectados menores a $0.025 \mathrm{mmol} / \mathrm{min}$.

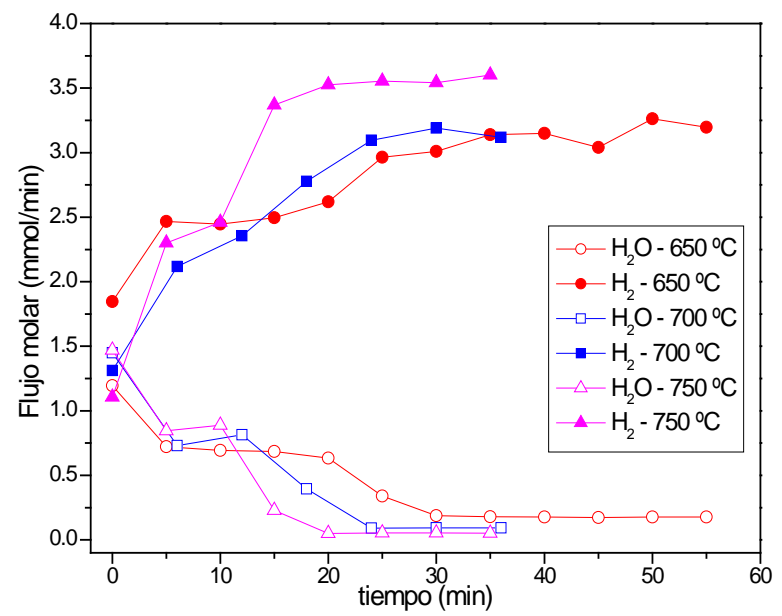

Figura 2. Influencia de la temperatura de reducción sobre la distribución de $\mathrm{H}_{2}$ y $\mathrm{H}_{2} \mathrm{O}$ a partir de óxido fresco.

\section{Conclusiones}

En todas las condiciones probadas existe una completa descomposición del etanol debido a la actividad catalítica del sólido, cuyos productos $\left(\mathrm{H}_{2}\right.$, CO y coque), son capaces de reducir el óxido de hierro a hierro metálico en su totalidad. Además, se observa que cuanto menor es la temperatura de reducción, mayor es la cantidad de coque producido. En las etapas de oxidación a $500{ }^{\circ} \mathrm{C}$, es posible la generación inicial máxima potencial de hidrógeno (primer ciclo). Sin embargo, a medida que se aumenta el número de ciclo, la recuperación de hidrógeno por parte del sólido es menor cuanto más alta es la temperatura de reducción previa.

\section{REFERENCIAS}

[1] W. Li, H. Wang, Z. Ren, G. Wang, J. Bai, Co-production of hydrogen and multi-wall carbon nanotubes from ethanol decomposition over $\mathrm{Fe} / \mathrm{Al}_{2} \mathrm{O}_{3}$ catalysts, Applied Catalysis B: Environmental, 84, pp. 433-439, 2008.

[2] M. Bertero, G. de la Puente, U. Sedran, Fuels from bio-oils: Bio-oil production from different residual sources, characterization and thermal conditioning, Fuel, 95, pp. 263271, 2012.

[3] E. Lorente, J.A. Peña, J. Herguido, Separation and storage of hydrogen by steam-iron process: Effect of added metals upon hydrogen release and solid stability, Journal of Power Sources, 192, pp 224-229, 200. 